\title{
A problematização da relação Rússia-OTAN: Dois pesos iguais no sistema?
}

\author{
Daniel Peixoto ${ }^{1}$, Enzo Tabet ${ }^{2}$, Higor França ${ }^{3}$, Luisa Reis ${ }^{4}$ e Renato Bahia ${ }^{5}$
}

\section{Resumo}

O propósito deste artigo é entender as relações entre a Rússia e a OTAN, no período pós - Guerra Fria, tendo em vista o momento de inclusão dos Estados Bálticos na Organização, em 2004, utilizando-se da pergunta: por que a Rússia não entrou em um conflito direto - ou mesmo interviu de alguma forma mais direta - na região ou no processo de decisão da OTAN, visto que essa inclusão estaria ameaçando o status russo como uma potência mundial e regional, principalmente em sua considerada "área de influência”. Com o auxílio da teoria realista neoclássica, será dado um foco na tomada de decisão da política externa do governo russo, delimitado pelo rastreamento de processo no método qualitativo. $O$ estudo de política externa nas Relações Internacionais pela academia está se desenvolvendo com uma atenção especial a abordagem neoclássica, que trabalha com a estrutura de poder impactando no processo de formação da política externa. No presente artigo, então, será rastreado como a estrutura afetou as visões do presidente Vladimir Putin, que decidiu implementar uma política específica com a OTAN em vista dos interesses russos no sistema internacional

\section{Palavras-chave}

Rússia, OTAN, Bálticos, Wohlforth, Realismo neoclássico

\section{Abstract}

The purpose of this article is to understand the relation between NATO and Russia in the post - Cold War period, in view of the moment of inclusion of the Baltic States in the Organization, in 2004. Our main question would be: why did Russianot entered in a direct conflict - or intervened in any strong way - within the Region or NATO, since that inclusion was threatening the Russian status as a world and regional power, particularly in it's home region. Within the background of the neoclassic realist theory, a focus will be given to the foreign policy decision - making of the Russian government delimitated by a process tracing in a qualitative method. The study of foreign policy in International Relations by the academy has been developing, with a special attention to the neoclassical approach, which works with a structure of power impacting the process of formation of foreign policy. In the present article, therefore, it will be traced how the structure affected the views of the president Vladimir Putin, who decided to implement a specific politic with NATO in view of the Russian interests in the international system.

\footnotetext{
${ }^{1}$ Daniel Peixoto é aluno do curso de graduação em Relações Internacionais do IRI/PUC-Rio.

${ }^{2}$ Enzo Tabet é aluno do curso de graduação em Relações Internacionais do IRI/PUC-Rio.

${ }^{3}$ Higor França é aluno do curso de graduação em Relações Internacionais do IRI/PUC-Rio.

${ }^{4}$ Luiza Reis é aluna do curso de graduação em Relações Internacionais do IRI/PUC-Rio.

${ }^{5}$ Renato Bahia é aluno do curso de graduação em Relações Internacionais do IRI/PUC-Rio.
} 
CADERNOS DE RELAÇÕES INTERNACIONAIS, v. 5, n.1, 2012

\section{Keywords}

Russia, NATO, Baltics, Wohlforth, Neoclassical Realism 


\section{Introdução}

A relação entre Rússia e OTAN no pós-Guerra Fria pode ser entendida por meio de uma análise estrutural das capacidades de poder entre ambas e das percepções dos tomadores de decisão dos países envolvidos, advinda da teoria realista neoclássica (Rose, 1998, p.151). Esta teoria propõe uma nova forma de auxiliar nos estudos de análise de política externa, em que são levados em conta não só as variáveis independente e dependente (Ibid., p.169), mas também uma variável interveniente, que seria a percepção do tomador de decisão e a estrutura doméstica do Estado (Ibid., p.153).

Deste modo, nossa pergunta de pesquisa seria: por que a Rússia decidiu tomar uma posição de não enfrentamento com a OTAN em 2004 quando os países bálticos foram incluídos nesta organização? Tendo como tema a análise das condições para a resposta mais tímida da Rússia perante a consolidação da expansão da OTAN para o mar báltico, em 2004, a teoria neoclássica se mostra eficaz. Identifica-se como a variável independente a estrutura do sistema internacional - ou seja, as capacidades relativas de poder -, a variável interveniente a percepção de Vladimir Putin - tomador de decisão russo- e como variável dependente a reação moderada russa. Utilizaremos, também, o método qualitativo de estudo de caso, trabalhando com o rastreamento de processo tendo em vista a presença de uma variável interveniente.

O método qualitativo auxilia em estudos mais específicos e detalhados sobre um determinado caso, na busca de um entendimento mais profundo que possa trazer novas conclusões e explicações sobre fenômenos históricos (Ragin, 1994). Ao invés de se focar em estudos mais amplos e se basear em números e estatísticas, direciona-se para o papel das ideias e das suas transformações, que trabalham em conjunto com a relação das capacidades de poder definida pela estrutura com a percepção dos formadores de política externa (Wohlforth, 1994-1995, p.94-95).

Utilizando-se do rastreamento de processo é possível entender a influência da variável interveniente entre a variável independente e dependente, podendo-se fazer um estudo de caso mais completo e detalhado. O uso de uma teoria auxilia no rastreamento de um caso, a fim de, por meio de uma forma dedutiva, conseguir chegar a uma 
conclusão por meio do auxílio promovido pela teoria trabalhada (Bennet 2004, p. 2223).

O estudo de caso do presente artigo será a expansão da OTAN para os bálticos, em 2004, chegando à fronteira com a Rússia,quando a organização incluiu a Estônia, Letônia e Lituânia. Acredita-se que embora a opinião pública russa tenha entendido a entrada dos países bálticos como uma ameaça do Ocidente à segurança russa, as disparidades de poder existentes entre Rússia e OTAN deixavam os russos em uma situação desfavorável na qual não tinham poder para impedir tal ação ocidental.

Dentro destes fatores, nossa hipótese é que as assimetrias de capacidade de poder já existentes entre Rússia e OTAN não permitiram a Rússia se opor com eficiência ao alargamento da organização. O então presidente Vladimir Putin percebendo que a Rússia não se encontrava na mesma posição que a Organização do Tratado do Atlântico Norte, entendeu que não teria condições para realizar uma intervenção ou ação que impedisse o alargamento para suas fronteiras, que ainda colocariam em risco os interesses do país com a União Europeia e a Ásia (Selezneva, 2002, p.17-18). Putin, então, decide demonstrar a insatisfação russa com o alargamento da OTAN por meio de protestos diplomáticos, que colocariam um equilíbrio entre a população e os interesses econômicos e políticos russos, dado os novos rumos tomados entre ambos os lados após os atentados terroristas de 11 de setembro de 2001 nos Estados Unidos. Em suma, a tomada de decisão de Putin por meio de rechaços diplomáticos não colocou em evidência a realidade russa em uma contínua e ampla disparidade militar para com a OTAN e manteve a integridade das suas relações comerciais.

A estrutura do artigo será pautada na explicação da variável independente e da variável interveniente para, então, chegar-se a variável dependente e entender se a hipótese apresentada é corroborada ou não. A segunda seção do artigo apresenta uma discussão com a literatura e define o marco teórico a ser seguido neste artigo. Posteriomente, estuda-se as capacidades relativas de poder da OTAN, traçando o papel desta organização no pós-Guerra Fria por meio da ideia de ampliação de suas funções. $\mathrm{Na}$ quarta seção procura-se perceber como a estrutura internacional afetou as percepções de Vladimir Putin quando este precisou dar uma resposta à imersão da OTAN pelo Leste Europeu, em que o presidente russo passa a enxergar uma maior 
disparidade de poder entre ambos. Na quinta seção mostrar-se-á qual foi a reação russa ao ato consumado, tendo em vista a influência da variável independente e dependente. Por fim, a conclusão busca um novo entendimento sobre as relações Rússia-OTAN no pós-Guerra Fria.

\section{Poder e modificação do sistema}

Ao analisar o realismo neoclássico, Gideon Rose afirma que é o poder relativo dos Estados que vai definir sua influência no sistema internacional. E é essa estrutura sistêmica que irá afetar os tomadores de decisão e formar suas visões sobre o ambiente externo, pois para os autores neoclássicos, ter um enfoque somente nas capacidades relativas não é suficiente para se entender e explicar o comportamento estatal. Os autores que seguem essa teoria defendem uma linha de pensamento pautada nas capacidades de poder sendo entendidas e refletidas pelos tomadores de decisão, pois só assim se pode entender como a estrutura afeta o comportamento dos Estados (Rose, 1998, p.158).

Segundo o realismo neoclássico, o sistema internacional é anárquico, o que cria um ambiente de dúvida e desconfiança entre os Estados - que são atores racionais e egoístas -, tentando contornar as incertezas por uma forma de controle do ambiente externo que os permeia. A preocupação então é focada na forma pela qual eles podem influenciar o sistema internacional e não na segurança (Ibid., p.152) e para isso, tendem a querer moldar e procurar uma mudança no sistema quando têm as capacidades de poder para tal (Ibid., p.162).

\footnotetext{
Thus neoclassical realism predicts that an increase in relative material power will lead eventually to a corresponding expansion in the ambition and scope of a country's foreign policy activity - and that a decrease in such power will lead eventually to a corresponding contraction. It also predicts that the process will not necessarily be gradual or uniform, however, because it will depend not solely on objective material trends but also on how political decision makers subjectively perceive them (Ibid., p.167).
}

Entre os autores neoclássicos, está William C. Wohlforth (1994-1995), que estuda o papel do realismo no pós-Guerra Fria, fazendo uma análise da queda da União Soviética que ratifica a utilidade e a importância do realismo como uma teoria que ajuda a entender determinados fenômenos. Em seu artigo, Realism and the End of the Cold 
War, Wohlforth tenta explicar por que a URSS caiu e vem rebatendo as críticas ao realismo, que não teria conseguido prever o fim do país comunista. Wohlforth acredita que o fim da Guerra Fria é fruto do declínio de poder relativo soviético e da confiança que isso deu aos Estados Unidos da América, mas que não pode esquecer-se da relação das capacidades de poder com a percepção do tomador de decisão, transformando sua forma de atuação política (Wohlforth, 1994-1995, p.96).

Os argumentos de Wohlforth serão usados como a principal base de auxilio teórico para este artigo, tendo o autor trabalhado com o rastreamento de processo para o seu estudo de caso - o fim da Guerra Fria. Ele explica como a estrutura de poder (variável independente) afetou a visão de Mikhail Gorbachev (variável interveniente) que se refletiu na política externa soviética (variável dependente) que foi levando gradualmente a desestabilização da URSS, e em última instância, ao seu fim (Ibid., p.109). A sua relevância está em apresentar como o fim da Guerra Fria acentuou uma já existente disparidade de poder entre Moscou e o Ocidente, que acaba afetando as decisões dos líderes em determinados casos.

William Wohlforth discorre como a Guerra Fria não foi um período de bipolaridade entre os Estados Unidos da América e a União Soviética, mas sim, entre a hegemonia norte-americana e o poder desafiador soviético, que não estava em um mesmo patamar que os EUA pelas diferenças nas capacidades. $\mathrm{O}$ autor afirma que a queda da União Soviética não foi o fim de um embate entre duas superpotências em um mesmo nível, mas de um potencial desafiador ao status quo norte-americano existente (Ibid., p. 98-99).

From 1917 onward, the Soviet Union stood formally for revision of the international status quo. Its real commitment to revisionism varied, and as its relative power grew its revisionist impulse assumed increasingly typical great-power forms. But country's post-1945 hegemonic status and consequent conservatism in the Central European region should not be confused with global hegemony. Worldwide, successive Soviet leaderships chafed against an American-dominated system. They never doubted who the real hegemon was (Ibid., p. 98).

O autor critica a visão de alguns teóricos que colocam como a causa da queda da União Soviética somente fatores domésticos, a exemplo dos problemas econômicos e das políticas de abertura - “perestroika” e "glasnost” -, sem levar em conta o papel da 
estrutura influenciando as decisões tomadas por Gorbachev (Ibid., p.108). Wohlforth não refuta a importância das políticas internas para o declínio soviético, mas deixa claro como elas são frutos da percepção do tomador de decisão tendo em vista as capacidades relativas de poder - nos quais os soviéticos estavam em desvantagem para com os EUA -, que acabavam trazendo para o Secretário Geral do Partido Comunista a situação de decadência de Moscou, a qual tentou evitar, por meio de suas medidas (Ibid., p.118).

Conseguinte, o embasamento teórico que Wohlforth desenvolve em torno do realismo neoclássico procurando novas conclusões sobre o declínio da União Soviética, auxiliam na produção deste artigo. Por meio da análise de política externa do período de Gorbachev, que tendo suas ideias e visões modificadas pelas diferenças de capacidades com os Estados Unidos dadas pela estrutura, Wohlforth traz uma leitura do internacional que se pauta na atual relação entre a Rússia e a OTAN.

Dada as suas diferenças de poder no sistema, que afetam diretamente a visão de Vladimir Putin e tangenciam as suas decisões, Wohlforth mostra como o realismo neoclássico consegue ser uma teoria que vem para tentar cobrir os leques de outras correntes que se estabelecem apenas em discursos estruturais ou domésticos.

Dessa forma, pode-se pensar no realismo neoclássico como uma alternativa ao debate existente sobre o tema proposto, isto é, a relação Rússia-OTAN no período póssoviético. O que a academia demonstrou foi uma preocupação que se refletiu nos debates teóricos do período quanto à agência, quanto ao que seria mais importante em termos de fator decisório, se a estrutura ou a agência. Afinal, se a primeira influi no comportamento dos agentes, é influenciada pelos mesmos (Giddens, 1986).

\section{A OTAN no Báltico: alargamento e projeção de poder}

Nesta seção do artigo pretendemos traçar um parâmetro sobre a atuação da Organização do Tratado do Atlântico Norte na região báltica, de forma a entender a pressão sistêmica ocidental por sobre a região. Para tal, vamos explicar brevemente os propósitos de criação da OTAN e sua mudança de objetivo após o término da Guerra Fria. Em seguida vamos relacionar o seu alargamento e uma intensificação da sua presença na região dos Bálcãs. 


\title{
A Organização
}

A Organização do Tratado do Atlântico Norte surgiu em 1949 por meio da assinatura do acordo que originou seu nome. Neste documento, os países signatários Bélgica, Canadá, EUA, França, Islândia, Itália, Luxemburgo, Noruega, Países Baixos, Portugal e Reino Unido - reafirmaram seus compromissos com princípios democráticos, pretendendo preservar a paz e a estabilidade na região do Atlântico do Norte por meio do reforço da sua segurança coletiva. Neste âmbito, o artigo 5 reflete bem seus propósitos:

\begin{abstract}
The Parties agree that an armed attack against one or more of them in Europe or North America shall be considered an attack against them all and consequently they agree that, if such an armed attack occurs, each of them, in exercise of the right of individual or collective self-defence recognised by Article 51 of the Charter of the United Nations, will assist the Party or Parties so attacked by taking forthwith, individually and in concert with the other Parties, such action as it deems necessary, including the use of armed force, to restore and maintain the security of the North Atlantic area (NATO, 1949).
\end{abstract}

No período da Guerra Fria, este discurso sobre segurança coletiva era de suma importância, uma vez que visava fazer frente à expansão soviética, principal ameaça aos Estados Unidos. A organização foi criada com o intuito de fornecer uma maior segurança em termos militares para o continente Europeu Ocidental, assim reafirmando a presença americana no continente e ao mesmo tempo concretizando o ensejo de países como a França e a Grã Bretanha de um continente mais estável, estimulando os processos de integração que já vinha ocorrendo no período (Judt, p.162, 2008).

A OTAN, liderada pelos norte-americanos e representando os seus interesses, também refletias as assimetrias de poder existentes entre a URSS e o ocidente (Wohlforth, 1994-1995, p.120). Principalmente, a partir do governo de Gorbachev, se tornava claro como que a própria União Soviética entendia o seu desnível de capacidades em relação à organização, o que na verdade só demonstrava uma realidade entre quem era o verdadeiro poder hegemônico e a potência em progressiva decadência (Ibid., p.120).

Percebendo que não estava em um mesmo nível de poder que a OTAN na Guerra Fria, a URSS procurou estabelecer uma maior cooperação com esta e o próprio Estados Unidos, mas que foi tratado pelo Ocidente de forma bem marginal. Tal situação só 
colocava a União Soviética em um patamar de inferioridade de poder cada vez maior (Ibid. p.123-124) e que só tendeu a crescer com a queda do bloco comunista, que demonstrou uma Rússia cada vez mais instável e com menor capacidade relativa de poder tangível. Disney reforça esta perspectiva: “[...] With the collapse of the Soviet Union, Russia lost not only territory but also influence, which made it sensitive to NATO's actions within its traditional 'sphere of influence' [...]” (Disney, s.d, p.40).

\section{O alargamento e sua relação com o Báltico}

Após o término da Guerra Fria, a OTAN se encontrou em um dilema: se a sua função de fazer frente às ameaças militares soviéticas havia sido extinta, então qual seria o futuro da organização? A resposta veio com o chamado "vácuo de poder” criado pelo fim do Pacto de Varsóvia e da retirada das tropas russas do leste europeu que foi percebido pela OTAN como uma forma de se manter por meio da prerrogativa da democracia (Ibid., p.36-37). Este seria um meio de se modernizar e reciclar a sua antiga função, garantindo a segurança no continente Europeu, principalmente a partir de uma política de expansão pela antiga área de influencia soviética, levando os ideais liberais ocidentais. (Ibid., p.36-37).

Com o fim da Guerra Fria, os países da região Báltica passaram a adotar uma postura de busca pela cooperação com o Ocidente. Essa busca por cooperação pode ser vista como uma forma de obter uma maior segurança em relação a algum tipo de retaliação por parte da Rússia no território. Outro fator importante deste alargamento para os países Bálticos foi o restabelecimento destes Estados como soberanos e procura por um reconhecimento do seu status internacional. Estes Estados possuíam uma visão securitizada da Rússia como um hegemon agressivo e revanchista, justificando, portanto, sua busca por uma aproximação militar com a OTAN (Browning et Joenniemi, 2004, p.10).

A própria Rússia adotou um discurso agressivo no período, primeiramente alegando à OTAN que esta aliança militar exigiria uma estratégia de defesa mais militarizada por parte de Moscou. Da mesma forma, disseminou uma imagem negativa dos países Bálticos para a organização ao condenar o tratamento a que eram submetidas as minorias russas nesses países. Vemos nessa situação uma percepção da própria 
Rússia do aumento do poderio militar da OTAN (Ibid., p.12). O alargamento seria apenas a expressão da política da OTAN pós-1991, em que a inclusão da Estônia, Letônia e Lituânia seria a expressão da Organização como o status quo ao qual a Rússia não poderia rebater.

Podemos entender essa disparidade por meio da própria teoria de Wohlforth, utilizando o conceito de relações de poder e sua percepção por parte dos tomadores de decisão explicado anteriormente (Wohlforth, 1994-1995, p.96). A OTAN, após o seu alargamento, aumentou de forma significativa suas capacidades relativas: integrou novos países em sua constituição, gerando um aumento na capacidade de projeção de poder e influência para o entorno russo e a Ásia central e seu potencial energético. Concomitantemente, isso levou a uma percepção dos tomadores de decisão russos das disparidades entre as capacidades relativas de ambos e uma reação por parte dos mesmos, como forma de responder ao fato; resposta essa que demonstra claramente o afastamento russo da disputa e uma busca por maior diálogo com a OTAN (Godzimirski, 2005, p.69).

O caso dos Bálcãs é emblemático para mostrar a percepção russa desse abismo do poder militar entre ambos. No Kosovo, por exemplo, a intervenção da OTAN no conflito fazia parte do novo propósito da organização em implementar intervenções humanitárias. A Rússia percebeu essa ação como uma clara demonstração dos possíveis contornos agressivos da OTAN, onde as autoridades do enfraquecido país perceberam que não poderiam seguir com um embate frontal com a organização, já que seria demasiadamente custosa e inviável, dado a extrema assimetria de poder existente, que deixaria a Rússia sem condições para travar um conflito. Portanto, passaram a adotar um discurso de crítica velada às intervenções da OTAN e procuraram se estabelecer como um país intermediário no processo de pacificação do Kosovo, buscando uma maior cooperação com a própria OTAN (Hedenskog et al, p.57, 2005).

\section{As percepções de Pution}

Nesta seção, buscaremos demonstrar como fatores internos e externos contribuíram para moldar a percepção em relação às capacidades e prioridades de interesses nacionais do principal tomador de decisão russo, o então presidente Vladmir 
Putin. Em outras palavras, nosso objetivo é rastrear a evolução das percepções internas nos debates de política externa russos no período pós-soviético, demonstrando como tais percepções serviram para definir a política externa russa no período e, por conseqüência, a reação do então presidente à segunda leva do alargamento da OTAN. Dividiremos esta seção da seguinte forma: primeiramente justificaremos essa seção perante nosso marco teórico, para, em seguida, traçar como se construiu o processo de tomada de decisão no meio doméstico russo, fazendo uma breve digressão sobre os rumos da política interna russa e como foi influenciada pelo exterior.

Segundo Wohlforth, o que ocasionou o fim da Guerra Fria foi, sobretudo, a perda de poder relativo do desafiante, a URSS. Devendo ser considerados, ainda, a percepção dos líderes soviéticos quanto a este fato (Wohlforth, 1994-1995, p.98). Em outras palavras, no realismo neoclássico, os Estados estão mais preocupados com sua capacidade de influenciar o sistema, baseando-se em suas capacidades relativas às outras potências devido ao seu medo das incertezas do sistema internacional (Rose, 1998, p.152). Nas palavras do próprio Wohlforth:

The corollary of a perceptual approach to Power is the realization that expectations inform policy. All policies are future-oriented. All decisions are bets on the future. A decision to reform, retrench or go to war reflects expectations about future trends and assessments of the likely effect of today's policies on tomorrow's distribution of relative power (Wohlforth, 1994-1995, p.98).

Ao assumir o governo russo, inicialmente como primeiro-ministro em 1999, Vladimir Putin teve que enfrentar uma economia em colapso devido à crise de 1998, um exército incompetente e decadente, envolvido na complicada segunda guerra da Chechênia - a partir de 2000 - e tendo relações com a OTAN em seu "pior momento desde o começo do período pós-soviético” (Godzimirski, 2005; Rumer \& Wallander, 2004).

A Rússia seria, portanto, uma potência em declínio. Isso se demonstra, principalmente, se analisarmos o colapso econômico dos anos 1990: o PIB russo caiu em torno de $43 \%$ ao longo da década, ao mesmo tempo em que perdeu-se aproximadamente 8,8 milhões de empregos. A própria população encontrava-se em queda livre em termos demográficos, com altas taxas de suicídio, problemas com alcoolismo e tuberculose (Spulber, 2003; Selezneva, 2002). 
Sendo assim, mesmo a recuperação que o país apresentou no começo da década de 2000, pouco atenuou a grave situação. Mesmo que o presidente Putin tenha sido capaz de resolver uma série de problemas enfrentados pela política doméstica russa leia-se seu sucesso em reforçar o poder central estatal, reformar os impostos e combater os "barões industriais” oligarcas que, além de dominar importantes setores econômicos, se envolviam na política de forma direta - o poder russo não passava da sombra do que um dia foram as capacidades soviéticas (Rumer \& Wallander, 2004). Dessa forma, por mais que seja praticamente um consenso entre os acadêmicos de que Putin foi capaz de tornar a política externa russa mais pragmática e eficiente (Selezneva, 2002; Rumer \& Wallander, 2004; Godzimirski, 2005), sua capacidade de ação, na prática, em muito estava tolhida. Segundo Rumer \& Wallander:

These shortcomings [deficiências contemporâneas da década de 1990] will inevitably taint Russia's ability to help solve the most crucial global problems, to cooperate with other great powers, to improve global security and economic well-being, and to prove a reliable partner (Rumer \& Wallander, 2004, p. 61).

Dado esta breve demonstração das condições de poder da Rússia, buscaremos uma análise de discursos e documentos oficiais do governo Putin acerca das decisões de política externa Russa, como forma de demonstrar onde estava seu foco no período que vai desde o começo de seu primeiro mandato até o ano de 2004, quando ocorre a expansão de fato.

Durante uma coletiva de imprensa após a reunião do conselho de segurança do país, em 2000, ao ser indagado sobre a questão da Chechênia, Putin afirmou que

\footnotetext{
What's important for us here is not the negotiation process in itself but Russian security guarantees. What matters to us is to make sure no that one will ever be able to use Chechnya as a bridgehead to attack Russia, or to take advantage of the situation there, as was the case last summer (Putin, 2000).
}

Ao anunciar que "ninguém jamais poderá utilizar a Chechênia como uma justificativa para um ataque à Rússia”, pode-se perceber um reflexo da preocupação com a mudança de estratégia de ação da OTAN quanto a quando invadir ou atacar um determinado país. Afinal, não é difícil encontrar semelhanças entre os massacres de kosovares por parte dos sérvios e os de chechenos por parte dos Russos. É uma demonstração do que Godzimirski quis dizer ao afirmar que os ataques aéreos da OTAN 
à Sérvia provocaram uma queda na qualidade das relações entre a Rússia e a OTAN (Godzimirski, 2005).

Já no final de março de 2001, em uma coletiva de imprensa após uma reunião com os membros do conselho da União Europeia (UE), Putin afirma que:

\begin{abstract}
Then, of course, there are the problems created by the enlargement of the European Union for Russia and some of our partners, including those connected with Russia's Kaliningrad Region, which will become an enclave surrounded by European Union countries on all sides. I thought it was important to tell our colleagues, as we did, that we must not merely neutralise the possible negative consequences for Russia, but on the contrary, use the advantages that the enlargement of the European Union undoubtedly offers (Putin, 2001).
\end{abstract}

Apesar de demonstrar preocupação com o enclave de Kaliningrado (antiga Konigsberg), Putin demonstra que uma expansão da União Europeia para o leste europeu não seria vista de forma negativa, uma vez que aproximaria os laços comerciais entre a dependente economia russa e a economia da UE. Tal comentário entraria em acordo com o discurso anual para a DUMA, apenas alguns dias mais tarde, no começo de abril, quando afirma que "we must act in the foreign policy sphere to protect our country's economic interests and the interests of Russian business and Russian citizens." (Putin, 2001) e que "it is a matter of principle for us that our international partners also respect and consider our national interests. This applies completely also to discussion of questions regarding strategic stability, disarmament, NATO expansion and forming the foundations of the world order in the twenty-first century” (Putin, 2001). Em outras palavras, pode-se inferir que, apesar de favorável a um alargamento do bloco da UE e do aprofundamento das relações comerciais com o Ocidente, este deveria respeitar os interesses russos, ou seja, respeitar suas necessidades de segurança que a expansão da OTAN representaria.

Em 2002, o discurso anual para a DUMA, quanto ao tópico de política externa, mantém o rumo de intensificação comercial com o Ocidente e, também, aproximação com a OTAN após os ataques de 11 de setembro. A Rússia passaria a se considerar como imprescindível para a estabilidade mundial. Nas palavras de Putin, “Our major goal in foreign policy is to ensure strategic stability in the world.” (Putin, 2002). Godzimirski explora, ainda, a visão de que, com os ataques Putin teria abraçado a causa 
da Guerra ao Terrorismo - incluindo o movimento separatista Checheno nesta categoria - como uma forma não só de mudar o foco de ação da OTAN para a Ásia Central (Afeganistão), mas também para tentar controlar os membros políticos da oposição mais exaltado-nacionalista anti-ocidental que o país ainda herdava do período soviético. Por essa mesma razão que, ainda em novembro de 2002, quando anunciado os planos de alargamento da OTAN para os Bálticos, Putin não fez grandes protestos (G Godzimirski, 2005; Putin, 2002).

Finalmente, em 2004, poucos dias após a expansão da OTAN para a região do leste europeu, Putin, em uma reunião com o secretário-geral da OTAN, Jaap de Hoop Scheffer, afirmou que:

[...] our attitude to the problem of NATO expansion, this position is wellknown, and it remains unchanged. And indeed, experience shows that this mechanical expansion does not allow us to effectively oppose the primary threats that we face today. This expansion cannot prevent, for example, terrorist acts in Madrid or help us to solve the problem of rebuilding Afghanistan. But there are also elements which we should pay attention to, and which we should agree on. Every country has the right to choose the option that it considers most effective for ensuring its own security. And secondly, perhaps most importantly: we hope that the expansion will help strengthen trust in Europe, and all over the world, and will be a tool and component of international security. To achieve this, it is of course necessary to raise the degree of trust between NATO and Russia, and this is why I began the talk with the expansion and strengthening of the Russia-NATO council, which we consider to be very important (Putin, 2004).

Pode-se inferir, a partir daí, que, dados os contextos de aproximação e intensificação econômica com a UE, aproximação com a OTAN - por meio da luta contra o terrorismo -, a Rússia, apesar de ainda questionar “a utilidade” de tal expansão, pôde aceitá-la com muito mais tranqüilidade que o faria caso isto ocorresse alguns anos antes, após a crise no Kosovo, por exemplo. Pode-se observar, ainda, a partir das últimas frases destacadas, o desejo de Putin de manter a, digamos, mecânica da expansão da OTAN durante a última década, de que sempre que a aliança fazia alguma movimentação que desagradasse fortemente os russos - mesmo que estes não tivessem poder para contestar tal ação -, esta faria alguma concessão futura - mesmo que em sua maioria dos casos simbólica - como forma de tentar garantir alguma legitimidade interna para os governantes russos (Smith, 2002; Rumer \& Wallander, 2004). 


\section{A Relação russa com os países Bálticos}

Nesta seção buscaremos analisar o reflexo da estrutura no comportamento do Estado russo, tendo passado pela interpretação do então presidente Vladimir Putin. Nesse sentido, o estudo apresentado será voltado para a variável dependente do caso estudado, ou seja, a reação internacional da Rússia à expansão da OTAN com a entrada dos três países Bálticos - Lituânia, Estônia e Letônia -, no ano de 2004. Buscaremos primeiramente analisar a razão por trás do intenso atrito entre esses países do leste europeu e a Rússia. Em seguida analisaremos a forma como cada país báltico encarou a possibilidade de uma expansão da OTAN. Por fim, veremos de que forma a própria Rússia reagiu após a expansão.

A Rússia e os países Bálticos têm um histórico de relações conturbadas. Letônia, Lituânia e Estônia possuem um passado em comum no que diz respeito à extinta União Soviética, o que em muitos aspectos ajuda a entender o interesse desses três países em uma expansão da OTAN (Disney, s.d, p.37). Os países Bálticos sempre viram sua incorporação à União Soviética como um ato de anexação e, em muitos aspectos, como um ato ilegal. Apesar de constantes tentativas, sobretudo pela Letônia e Lituânia, de fazer o Estado russo reconhecer a incorporação como uma anexação, o que implicaria numa situação de ocupação soviética, o governo russo jamais cedeu tal reconhecimento (Ibid. p.38). O problema dessa situação é o reflexo gerado na relação entre esses países, sobretudo a Letônia e Estônia, para com os direitos civis das minorias russas que ali se encontravam (Pikayev, 2005, p.13-14).

A visão russa dessa relação conturbada se caracteriza como sendo receosa, sobretudo tendo em vistaa diminuição do seu papel no cenário internacional. Por ser a herdeira da URSS, a Rússia pós-Guerra Fria ainda considerava tal região báltica como sendo parte de sua esfera de influência (Kubickek, 1999-2000). Porém, o fim da União Soviética trouxe junto com a perda territorial, uma perda relativa de influência nas mesmas regiões, que agora eram território estrangeiro. Em outras palavras, "the Russian Federation (RF) inherited everything from the USSR except its territorial integrity, secure borders and a sense of being an impregnable power” (Black, 2000, p.7). Portanto, não foi uma surpresa quando, em 1997, a Rússia ameaçou impor sanções econômicas à Estônia caso ela prosseguisse com sua iniciativa política de ingresso à 
OTAN (Disney, s.d, p.41). De fato, em termos materiais, tal expansão da OTAN com esses três novos países não apresentava tanta ameaça para os interesses russos. Entretanto, para a identidade internacional russa no período pós-soviético, a proposta poderia se apresentar como um abalo a sua noção inerente "grande potência” (Lynch, 2001, p.18).

Então, tendo em vista a relação complexa entre a Rússia e os países do Báltico, o que os últimos buscavam em potencial com um ingresso na OTAN? No período da década de 1990, os países Bálticos pareciam ter linhas gerais parecidas no que diz respeito à defesa de uma aproximação para com o Ocidente, mais especificamente a OTAN, derivado de um ceticismo de sua parte em relação à estabilidade da democracia russa. Havia receios nesses países de que uma possível instabilidade política na Rússia e a chegada de nacionalistas ao poder apresentassem uma ameaça à segurança da região do Mar Báltico (Disey, s.d, p.39).

Essa preocupação foi apresentada indiretamente na National Security Concept da Estônia, que coloca a entrada na OTAN como sendo a melhor forma de proteger e consolidar o Estado democrático na região (National Security Concept of the Republic of Estonia, 2001.). Similarmente, a National Security Concept da Lituânia expressa confiança na entrada do país na OTAN também afirmando que esta garantiria não só a estabilidade e segurança interna dos Estados, mas da região (National Security Concept of the Republic of Lithuania, 2002). Por fim a State Defense Concept da Letônia divide a opinião de uma estabilidade garantida com uma participação na OTAN (State Defense Concept of the Republic of Latvia, 2003). A sociedade civil de cada país também estava de acordo com sua entrada na organização, com 65\% na Estônia, 64\% na Letônia, e 84\% na Lituânia da população apoiando um ingresso oficial desses países na OTAN no ano de 1996 (Kostadinova apud Disney, s.d, p.40). De fato, a instabilidade política na Rússia não se apresentou da forma esperada, com receio, por parte desses países. Porém, podemos perceber uma tendência ao analisar tais informações. Observamos a presença de um forte interesse dos países Bálticos em obter uma maior autonomia frente a um vizinho que visava, desde o começo da década de 1990 até o início dos anos 2000, frear qualquer perda na sua dita esfera de influência. Assim sendo, como se deu a reação russa à entrada dos países Bálticos em 2004 e, portanto, à expansão da OTAN de 
encontro à fronteira territorial russa? O próprio comportamento dos países Bálticos poderia trazer uma intensificação desse atrito Rússia-Bálticos. A partir do ingresso à OTAN, esses países passaram a apresentar uma conduta mais arrojada, como colocado por Disney "Estonia, Latvia and Lithuania have if anything become more strident in their interaction with Russia” (Disney, s.d, p.48). Adicionado a isso temos a tentativa por parte dos países bálticos de exercer influência nos Estados pertencentes à Comunidade dos Estados Independentes (Karabeshkin \& Spechler, 2007), espaço visto pelo país russo como sendo tradicionalmente sua esfera de influência (Disney, s.d, p.48). Uma nota divulgada no site oficial da OTAN, elaborado por Tomás Valásek ${ }^{6}$ aponta justamente esse posicionamento, reflexo da relação complicada entre os países, colocando que "The Baltic states in particular are far more focused on Russia than any of the old Allies, and also less likely to be willing to compromise.” (Valásek, 2004).

Ao analisar com maior cuidado a repercussão da expansão nas políticas russas nos anos seguintes, percebemos um comportamento ameno contrariando o que se esperava por parte dos países Bálticos, tendo em vista a tendência nacionalista do governo Putin para com o entorno regional russo. É importante ressaltar nesse momento que o “comportamento ameno” constatado diz respeito a uma ausência de repercussões políticas de fato, como sanções por exemplo. Em termos retóricos, a reação russa ao alargamento foi negativa, tendo protestando veementemente. Porém, em termos de relações econômicas e cooperativas, sobretudo para com o Ocidente, percebe-se pouca mudança do lado russo. Um exemplo disso foi a criação do Conselho OTAN-Rússia, em maio de 2002, que estabelecia áreas de cooperação entre as partes e que não foi afetado pela concretização do alargamento da Organização (Disney, s.d, 47). Segundo Lynch (2001, p. 18): “Indeed, Russia's primary fear about the consequences of NATO expansion is that Russia will be strategically isolated from a Europe, East and West, that is committed to a course of comprehensive economic, political and strategic integration”.

Torna-se, então, notável uma preocupação maior com o futuro da manutenção da cooperação, sobretudo aquela voltada para a recuperação econômica da Rússia, e não

\footnotetext{
${ }^{6}$ Diretor do escritório bruxelense do "Center for Defense Information", um think-tank independente focado em temas de segurança
} 
um posicionamento reativo em termos práticos voltado para a defesa de uma posição de influência. Em muitos aspectos, foi percebido pelos tomadores de decisão na Rússia que uma reação agressiva, ou de sanções, traria conseqüências negativas e se tornaria um empecilho para a possibilidade de negociação de acordos bi ou multilaterais, que poderiam trazer vantagens à Rússia. Ao contrário da União Soviética, a Rússia possui a capacidade de cooperar com diversos Estados integrantes da OTAN (Lynch, 2001). Em discurso feito pelo então presidente Vladimir Putin durante uma Sessão Plenária dos Embaixadores da Federação Russa e Representantes Permanentes, em julho de 2004, poucos meses após o alargamento, é perceptível o tom, apesar de receoso, voltado para um viés mais cooperativo do que se era especulado:

Our other traditional priority is, of course, Europe ... The latest wave of EU and NATO expansion has created a new geopolitical situation on the continent, and the task now is not so much to adapt ourselves to it as, first, to minimize the potential risks and damage to Russia's economic security interests and, second, to find here advantages for ourselves and turn them to good account. Here, too, there is no alternative approach but to build up equal cooperation with the European Union and the North Atlantic Treaty Organization. A key element of such policy is development of ties with countries that show a real interest in closer contacts with Russia (Putin, 2004).

Neste discurso, Putin pode ser compreendido como a personificação da reação geral russa frente ao alargamento: criticas em relação ao que isso traria para o espaço russo na política internacional, mas ainda assim ciente da importância de manter a cooperação e o diálogo com a OTAN e a União Europeia visando manter os interesses russos considerados relevantes. Em suma, vemos pouca mudança efetiva na atuação russa mesmo com o alargamento da OTAN sendo um fato consumado. Lynch resume tal postura que se manteve desde o final dos anos 1990 e que pouco mudou com a expansão em si:

Russian foreign policy adopted a much less ideological stance, one predicated upon a more nationalist and unilateralist tone, while being careful not to take steps that could jeopardise its ties with the wealthy and powerful G-7 states on whose cooperation Russia continued to depend. (Lynch, 2001, p.21)

Portanto, o que se pode tirar de uma análise da relação russa com os países Bálticos antes e após a entrada dos últimos na OTAN? A realidade é que, além dos 
atritos já presentes derivados de um contexto histórico ainda não resolvido, pouco se mudou de fato na postura russa. A estratégia adotada pelo líder russo, de manter uma postura estável ao invés de reagir de modo enfático, se deu graças à importância dada ao novo contexto de cooperação com o Ocidente. Essa opção pode ser entendida ao analisarmos a complicada situação econômica russa e sua perda de influência no entorno regional, que foi inevitável a partir da década de 1990.

\section{Conclusão}

Ao longo desta pesquisa, procuramos demonstrar por meio da lente realista neoclássica as condicionantes da tomada de decisão de Vladimir Putin. Em outras palavras, nosso objetivo era observar a eficácia desta teoria, analisando-a por um estudo de caso específico, sendo neste artigo, a política externa russa face ao alargamento da OTAN, em 2004. Dentro do método qualitativo de pesquisa, utilizamos o rastreamento de processo para guiar nossa análise, tendo em vista que com ele é possível perceber a influência da variável interveniente - a percepção de Putin do aumento da diferença entre as capacidades relativas da Rússia e da OTAN; da variável independente - as capacidades relativas do sistema internacional; e a da variável dependente - a reação russa diante do alargamento da organização. Assim acreditamos que cobrimos um maior espectro de análise, gerando um estudo mais minucioso sobre o tema em questão, abordando não só uma visão estrutural de capacidades, como um rastreamento preciso da realidade doméstica russa, o que tornou nossa pesquisa mais completa

A base teórica de Wohlforth foi imprescindível para conseguirmos chegar à conclusão por meio do modo dedutivo. $\mathrm{O}$ autor, trabalhando a partir da estrutura influenciando nas percepções de Gorbachev e que teve seu fim no comportamento do Estado soviético, conseguiu examinar de forma minuciosa o fim da Guerra Fria com a queda da União Soviética (Ibid., p.126). A idéia que Wohlforth traz em todo o seu texto, desde os desníveis de poder existentes até a situação interna de Moscou da época, consegue fazer com que autor apresente uma nova explicação para o caso, enriquecendo ainda mais seu trabalho e servindo como uma base para a execução deste artigo. 
Percebemos que a escolha deste estudo de caso foi justificada pelas características únicas deste recém-formado Estado e pelas graves dificuldades que ele enfrentou logo de seu nascimento, em grande parte pelo estigma sofrido por ser o "herdeiro legítimo" da URSS. Dessa forma, podemos identificar as relações Rússia-OTAN-Bálticos como extremamente complexas, com diversas nuances que devem ser observadas, tanto no plano interno quanto externo. Por um lado, deve-se levar em consideração o jogo político entre Rússia e OTAN desde os anos 1990 quanto ao projeto de alargamento de uma forma praticamente padronizada, isto é, em "passos” específicos - em que primeiro a OTAN toma uma decisão de forma unilateral, a Rússia protesta, mas não possui meios de se opor de forma veemente. Ao mesmo tempo, a OTAN conduz a ação como planejada originalmente, mas permite aos russos uma forma de manter sua imagem, tanto internacionalmente quanto internamente - , pelo outro, deve-se considerar as rivalidades históricas entre Bálticos e Rússia no sentido de que há pouco ou nenhum espaço para a confiança por parte dos Bálticos, devido ao que eles consideram como sua “invasão e anexação” por parte da URSS (Disney, s.d. p.37). Ou seja, para estes países, a OTAN era a garantia de segurança e estabilidade de sua soberania ante ao gigantesco vizinho, considerando, ainda, que tal proteção entraria no novo protocolo de ação da OTAN, em defesa da democracia e livre mercado para garantir a paz no continente europeu.

Pode-se concluir, assim, que, a hipótese apresentada é corroborada com a pesquisa em questão, em que com a perda de capacidades por parte da Rússia desde o fim da Guerra Fria, cria-se um “vácuo de poder” na região, se tornando suscetível ao alargamento não só da OTAN, mas também da União Europeia. Isso acaba causando na Rússia não só uma crise política interna, uma vez que os russos percebiam sua identidade como potência se esvair, como também um temor quanto à possibilidade de isolamento por parte da civilização ocidental, da qual a Rússia é economicamente dependente. Deste modo, o país prefere não ir contra as políticas da OTAN, pelo contrário, passa a apoiar algumas ações, tendo em vista que a Rússia não dispunha das capacidades para rechaçar a organização. 


\section{Referências}

BENNETT, A. Case study methods: design, use, and comparative advantages. In: SPRINZ, D.F.; WOLINSKY-NAHMIAS, Y. (Ed.) Models, numbers, and cases: methods for studying International Relations. Ann Arbor: The University of Michigan Press, 2004, p.19-55

BLACK, J.L. Russia faces NATO expansion: bearing gifts or bearing arms?. Boston : Rowman \& Littlefield Publishers,2000.

DANNREUTHER, R. Escaping the enlargement trap in NATO-Russian relations. Survival, v. 41, n. 4, p. 145-164, 1999.

\section{DISNEY,T. How has NATO enlargement impacted on NATO-Russia relations? Disponível em http://www.groundings.co.uk/Content/2010edition/NATO\%20Enlargement.pdf (Acesso em : 4 jun. 2011)}

GIDDENS, A. The Constitution of Society. University of California Press, p.1-34, 1986

GODZIMIRSKI,J Cap. 3 In: HEDENSKOG,J.(Ed.) Russia as a great power: dimensions of security under Putin, Abingdom: Routledge, 2005

HEDENSKOG, J (Ed.) Russia as a Great Power: dimensions of Security under Putin. Abingdom. Nova Iorque, 2005

KARABESHKIN,L.A; SPECHLER, D.R. EU and NATO Enlargement: Russia's Expectations, Responses and Options for the future. European Security. v. 16 n. 3 \& 4, 2007. Disponível em http://www.informaworld.com/smpp/content $\sim \mathrm{db}=$ all $\sim$ content $=\mathrm{a} 787723380 \sim$ frm=titlelin k. (Acesso em : 8 jun. 2011)

KUBICEK,P. Russian Foreign Policy and the West. Political Science Quartely. v. 114, n. 4, Winter - 1999- 2000.

LYNCH. A,C. Ther Realism of Russia’s Foreign Policy. Europe-Asia Studies, v. 53 n. $1,2001$.

MIGNOLO, W. D. The Darker Side of the Renaissance: Colonization and the Discontinuity of the Classical Tradition. Renaissance Quarterly, v. 45, n. 4, p. 808828, 1 dez 1992. 
NATIONAL SECURITY CONCEPT OF THE REPUBLIC OF ESTONIA, 2001 Disponível em: http://web-static.vm.ee/static/failid/335/SecurityConcept.pdf (Acesso em: 8 jun. 2011).

NATIONAL SECURITY CONCEPT OF THE REPUBLIC OF LITHUANIA, 2002. Disponível em : http://merln.ndu.edu/whitepapers/LithuaniaNationalSecurity2002.doc (Acesso em : 8 jun. 2011).

PIKAYEV,A.A. A velvet divorce. Disponível em : http://www.gwu.edu/ ieresgwu/assets/docs/ponars/pm_0369.pdf (Acesso em : 04 jun. 2011)

PUTIN,V. News Conference Following Security Council Session, 2000. Disponível em : http://archive.kremlin.ru/eng/speeches/2000/04/21/0000_type82915_122367.shtml (Acesso em : 9 jun. 2011)

Disponível em

Press Conference following a Meeting with EU Council Members,2001. http://archive.kremlin.ru/eng/speeches/2001/03/23/0005_type82914type82915_138736. shtml (Acesso em : 9 jun. 2011)

Disponível

Annual Adress to the Federal Assembly of the Russian Federation, 2001. http://archive.kremlin.ru/eng/speeches/2001/04/03/0000_type70029type82912_70660.s

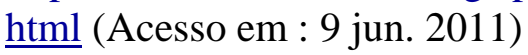

Roberston,2002.

Joint Press Conference with NATO Secretary General George http://archive.kremlin.ru/eng/speeches/2002/11/11/0002_type82914type82915_151543. shtml (Acesso em : 9 jun. 2011)

Annual Adress to the Federal Assembly of the Russian Federation,2002.

Disponível em: http://archive.kremlin.ru/eng/speeches/2002/04/18/0000_type70029type82912_70662.s $\underline{\mathrm{html}}$ (Acesso em : 9 jun. 2011)

Disponível

Meeting with NATO Secretary-General Jaap de Hoop Scheffer, 2004. http://archive.kremlin.ru/eng/speeches/2004/04/08/1806_type82914_63120.shtml

Acesso em : 9. jun. 2011) 
Speech at a Plenary Session of the Russian Federation Ambassadors and Permanent Representatives Meeting, 2004. Disponível em : http://archive.kremlin.ru/eng/speeches/2004/07/12/1323_type82912type82913type8477 9_74425.shtml (Acesso em : 6 jun. 2011)

RAGIN, C. Constructing social research: the unity and diversity of method. Thousand Oaks: Pine Forge Press, p. 81-104, 1994

ROSE, G. Neoclassical realism and theories of foreign policy. World Politcs. v. 51 n. 1 p. 144-172, 1998.

RUMMER \& WALLANDER. Russia: Power in Weakness? The Washington Quarterly. Winter 2003-2004, p. 57-73

SELEZNEVA,L. Post-soviet Russian Foreign Policy: Between doctrine and pragmatism. European Security. v. 11, n.4, p. 10.

STATE DEFENSE CONCEPT OF THE REPUBLIC OF LATVIA, 2003 Disponível em: http://www.am.gov.lv/en/security/basic/4537/ (Acesso em: 08 jun. 2011)

SMITH,M. A bumpy road to an unknown destination? NATO-Russia relations, 19912002. European Security. v.11, n. 4, p. 59-77.

SPULBER, N. Russia's economic transitions: from late tsarism to the new millennium. Cambridge: Cambridge University Press, 2003

WOHLFORTH, W. Realism and the end of the Cold War. International Security. v. 19, n. 3 p. 91-129, Inverno 1994-1995.

VALÁSEK,T. The meanings of enlargement. North Atlantic Treaty Organization. Disponível em : http://www.nato.int/docu/review/2004/issue2/english/art4.html (Acesso em : 4 jun. 2011) 